\title{
Ambulatory 23 hour recording of intraoesophageal pressures in normal volunteers: a propagation analysis from one proximal and two distal recording sites
}

\author{
S Kruse-Andersen, L Wallin, T Madsen
}

\begin{abstract}
pH data were obtained from one level and pressure data from three levels in the oesophagus over 23 hours in 24 healthy volunteers, followed by automatic propagation analysis of motility data and analysis of time with $\mathrm{pH}$ less than 4. Apart from periods of meal ingestion, isolated pressure complexes were found more frequently in the distal than in the proximal oesophagus. This was especially common in the recumbent position at night. Most contractions of the proximal oesophagus were propagating. In the distal oesophagus propagating pressure waves were more frequent during the day than during the night and most frequent during meals. The state of consciousness rather than body position per se is important in determining the frequency of simultaneous contractions in the distal oesophagus.
\end{abstract}

Ambulatory recording of intraoesophageal $\mathrm{pH}$ and pressure is frequently used to investigate oesophageal function..$^{1-5}$ There have been only a few reports of ambulatory recording of oesophageal motor activity using direct digital conversion of pressure signals and storage in solid state memories. $^{3-5}$ A more detailed report of the results from such recordings in normal subjects was published recently. ${ }^{4}$ Signals have been obtained from only two pressure channels and one $\mathrm{pH}$ channel, mainly because of problems of storage capacity.

The transport of a bolus through the oesophagus primarily depends on coordinated peristalsis. ${ }^{6-8}$ Therefore, one important objective when making ambulatory recordings of oesophageal motility is to be able to classify the pressure events on the basis of speed, direction of propagation, and distance of spread of the pressure waves through the oesophagus. Pressure events obtained from three levels of the oesophagus in normal volunteers under ambulatory conditions were analysed in the present study.

Oesophagus Laboratory, Department of CardioThoracic Surgery, Odense University Hospital, Odense, Denmark

$S$ Kruse-Andersen

L Wallin

T Madsen

Correspondence to: Dr S Kruse-Andersen Kløvervænget $14 \mathrm{D}$, DK-5000 Odense C, Denmark.

Accepted for publication 31 December 1990
Twenty four asymptomatic volunteers, 12 men and 12 women, median age 37 years (range 2258 , were studied. The median age for the men was 39 years and for the women 36 years. This difference was not significant. Five men and six women were smokers. None had experienced chest discomfort or symptoms of gastrointestinal disease and none had had surgery of the chest or upper abdomen. Nor were any on medical treatment. Informed consent was obtained from each volunteer and the investigation was approved by the local ethics committee.

\section{APPARATUS}

A combined $\mathrm{pH}$ and pressure probe was constructed from two standard pressure catheters (Sentron, The Netherlands) provided with radially oriented solid state pressure transducers, an open tip polyethylene catheter (Clay Adams PE 160), and a monocrystalline antimony pH probe (Monocrystant Mod 0011, Synectics Medical, Sweden). These were mutually fixed in a way that allowed continuous pressure measurements from three levels of the oesophagus. The distance between the middle and the distal transducer was $5 \mathrm{~cm}$ and between the middle and the proximal transducer $10 \mathrm{~cm}$. The most distal pressure transducer was located $3 \mathrm{~cm}$ proximal to the $\mathrm{pH}$ probe. The Clay Adams catheter, which had an internal diameter of $1 \cdot 14$ $\mathrm{mm}$ and an external diameter of $1.58 \mathrm{~mm}$, terminated $0.5 \mathrm{~cm}$ proximal to the distal solid state transducer. The transducers and the $\mathrm{pH}$ probe were connected to a portable recorder with a solid state memory (micro-DIGITRAPPEREXT, Synectics Medical) via a sensor adapter. This device permits sampling and data storage for at least 24 hours. Signals from each channel were digitised with a sampling frequency of $4 \mathrm{~Hz}$.

\section{EXPERIMENTAL CONDITIONS}

Recording was started in the afternoon between 630 and $800 \mathrm{pm}$ and stopped 23 to 24 hours later. Intake of food and beverages of low $\mathrm{pH}$ was not allowed during this time. This was, however, the only restriction. The subjects were free to decide when and for how long to have recumbent periods; tobacco and alcohol intake was permitted according to their usual habits. No restrictions were made regarding the timing of meals. Some of the subjects continued their usual work on the day of recording, but the majority spent the day at home. They were asked to carry out their usual daily activities including housework and work in the garden. They were, however, requested to keep a diary of the exact timing of meals and of the beginning and end of periods of recumbency. 

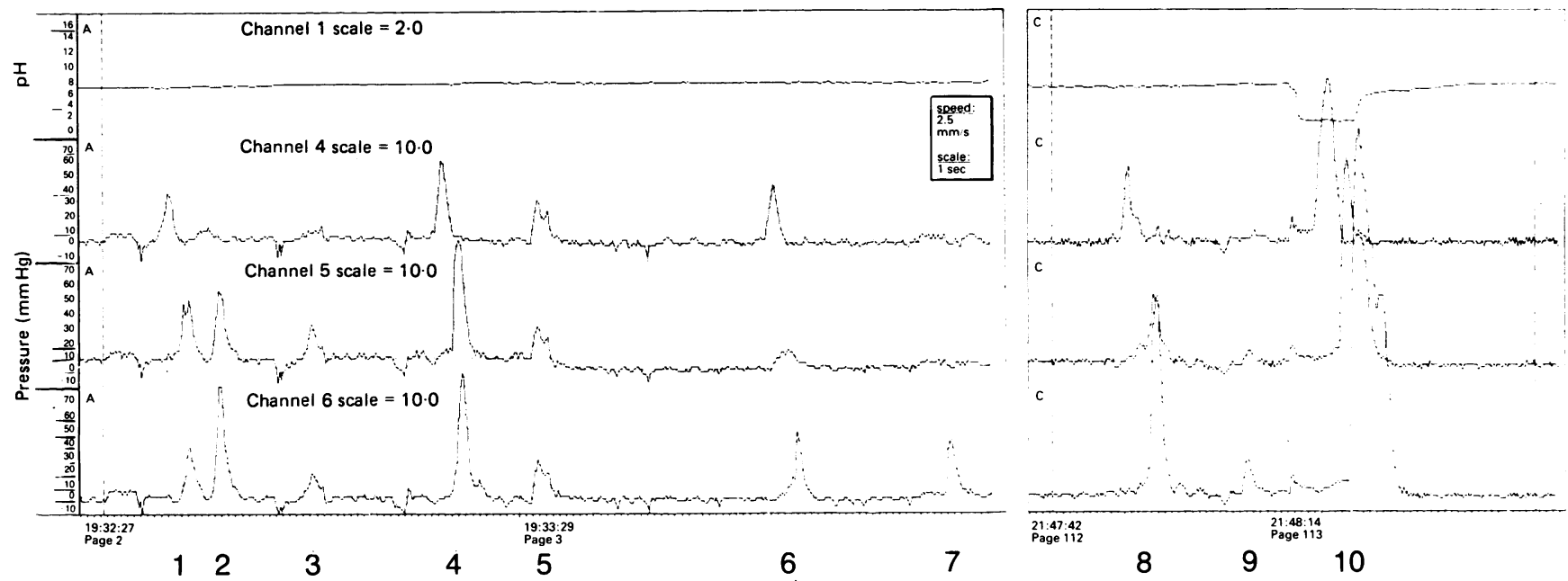

Figure 1: Two representative sections of a recording from one normal volunteer, showing two complete complexes (1 and 10) with propagation through all channels, two complete complexes $(4$ and 8$)$ being propagated proximally but developing into a simultaneous contraction more distally, and a complete complex being simultaneous at both levels (5). 2 and 3 are local distal simultaneous contractions. Thus propagation was frequent proximally, while simultaneous contractions predominated distally. 7 and 9 are distal segmentary contractions, and 6 was classified as two segmentary contractions because the middle pressure peak was below the amplitude threshold.

\section{EXPERIMENTAL PROCEDURE}

Calibration of $\mathrm{pH}$ and pressures was performed one hour before recording. $\mathrm{pH}$ calibration was performed in buffered solutions of $\mathrm{pH} \mathrm{7.01}$ and 1.07 (Buffer No 5001 and 5002, Synectics Medical). The pressure transducers were calibrated by successive application of external pressures of $0 \mathrm{~mm} \mathrm{Hg}$ and $50 \mathrm{~mm} \mathrm{Hg}$ by means of a water column. An external reference electrode (Hellige, Germany) was taped to the skin below the right clavicle. The catheter assembly was introduced transnasally and the tip advanced to the stomach, thus ensuring an acid $\mathrm{pH}$. The exact positioning of the probe was achieved with the subject in the supine position by means of the open tip catheter which was connected to a combined external transducer and flush system (Trantec Disposable 53-600, Baxter), providing a flow of $3 \mathrm{ml} / \mathrm{h}$. This method allowed positioning of the $\mathrm{pH}$ probe $5 \mathrm{~cm}$ proximal to the gastro-oesophageal sphincter by means of simultaneous infusion manometry and on-line transcription of the pressure curve on a mingograph (Siemens Elema 803). The probe was securely taped to the nose in the correct position, and the open tip catheter disconnected and sealed. The recording unit was fixed to the waist of the subject with a belt. After completion of recording the recording unit was disconnected and data transferred to an IBM computer by an optical interface (Combi interface 9506, Synectics Medical).

\section{DATA ANALYSIS}

The data were analysed by means of a programme designed for automatic motility analysis (Polygram, version 4.30 B1, Synectics Medical). A baseline was defined automatically through the most frequented level of the smaller pressure variations - that is, pressure variations not exceeding the detection level. The baseline was set to be auto-updated every 20 seconds. A relative pressure amplitude change of $15 \mathrm{~mm} \mathrm{Hg}$ was decided as the level for a pressure peak to be detected. ${ }^{4}$ Pressure deflections lasting less than one second or more than 15 seconds were not considered a valid contraction. The time for occurrence of a pressure deflection was the time where the detection threshold was first exceeded.

Pressure deflections that were time related within predetermined limits were considered as constituting a pressure complex, and the remaining contractions were classified as segmentary. Pressure deflections that were time related at the proximal and middle recording site were considered a proximal pressure complex, and these were subdivided into propagating, simultaneous, and reverse contractions. The same applies to pressure deflections that were time related at the middle and distal recording sites. A complete complex was noted if a complex contained pressure peaks that were time related at all levels. The remaining were denoted local complexes.

Propagating peristalsis was defined as a pressure wave through the oesophagus with an average velocity of 1.3 to $15 \mathrm{~cm} / \mathrm{s}$. The limits for simultaneous contractions were $\pm 15 \mathrm{~cm} / \mathrm{s}$ and for reverse peristalsis -15 to $-5 \mathrm{~cm} / \mathrm{s}$, negative values denoting pressure waves with the proximal peak occurring after the distal peak. These limits were based on previous prolonged intraoesophageal pressure recordings performed in our laboratory with stationary equipment ${ }^{9-11}$ and on our own normal limits for propagation of a wave during swallowing of liquid and solid boli, originally based on infusion manometry in normal subjects (unpublished data).

If a contraction had pressure peaks of sufficient amplitude to be detected at the proximal and distal channels, respectively, but at the same time incorporating a subthreshold peak at the middle channel, an upper and a lower segmentary contraction was detected by the program.

In addition to the analysis of the pressure data, the $\mathrm{pH}$ data were analysed for percentage of time with $\mathrm{pH}$ less than 4 . The diary information recorded by the subjects was entered into a diary spread sheet provided in the analysis program, 


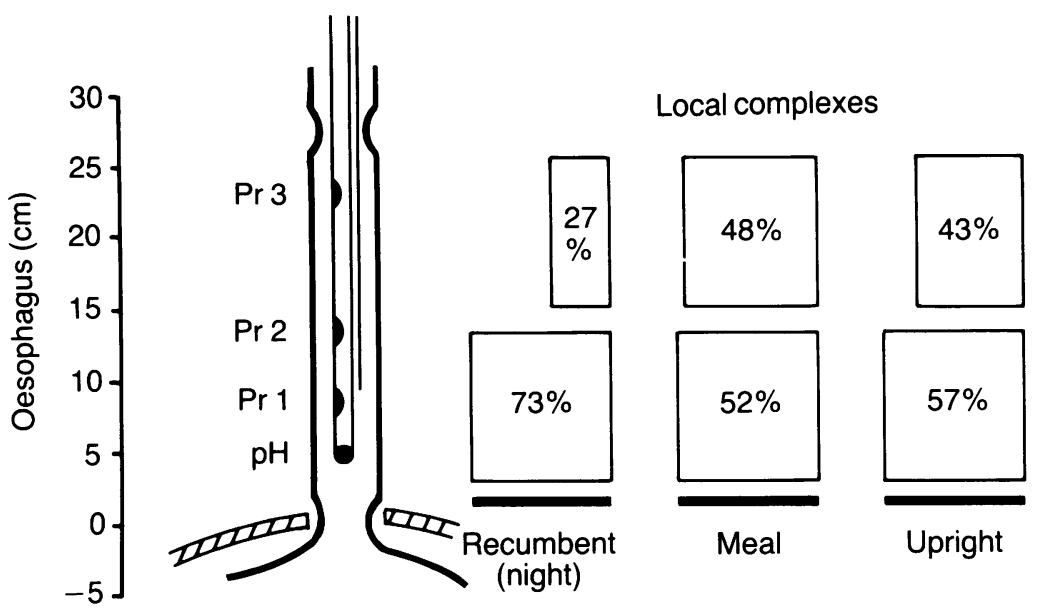

Figure 2: The proportions of local complexes (median values) that were detected between the proximal and the middle recording sites $(\operatorname{Pr} 2$ and 3) and between the middle and distal recording sites $(\operatorname{Pr} 1$ and 2$)$, respectively, under three different circumstances.

thus enabling automatic analysis of night time recumbency, daytime recumbency, meals, and remaining time in the upright position.

\section{STATISTICS}

Pratt's test and Friedman's test were used to compare data obtained under two or more differing circumstances, respectively. A multiple comparison procedure ${ }^{12}$ was carried out in cases of significant differences between more than two related samples. Correlation was evaluated by calculation of Spearman's rank correlation coefficient. $\mathrm{p}$ values less 0.05 were regarded as significant.

\section{Results}

The 24 subjects had $9 \cdot 0$ hours (range $7 \cdot 5-12 \cdot 4$ ) of night time recumbency, 11.7 hours (range $6 \cdot 3-15.0$ ) in the upright position, and 0.9 hours (range $0 \cdot 2-3 \cdot 7$ ) related to meal consumption. The total recording time was 23.4 hours (range $23 \cdot 0-24 \cdot 4)$. In the 17 subjects, who had periods of daytime recumbency, this amounted to $2 \cdot 6$ hours (range 0.3-6.8), 10.3 hours (range 6.313.7) in the upright position, and night time recumbency amounted to $9 \cdot 0$ hours (range $7 \cdot 6-$ $12 \cdot 4$ ). In addition, $0 \cdot 8$ hours (range $0 \cdot 2-2 \cdot 1$ ) were related to meal consumption. An original printout from one normal subject is shown in Figure 1.

A median of $23 \%$ (range 14-54) of the recorded pressure peaks was classified as segmentary contractions. Only one fifth of these were detected by the middle transducer, while the rest were approximately equally distributed between the proximal and the distal transducers. Thirty eight per cent of the contractions that were a part of a pressure complex were incorporated into a complete complex during the night, in contrast to $46 \%$ during meals and $45 \%$ in the upright position. During meal ingestion proximal and distal localised complexes were almost equally frequent (Fig 2). There were relatively more localised complexes distally than proximally during the remaining time upright $(p<0.004)$, and particularly during night time recumbency $(p<0 \cdot 00003)$, where approximately three of four localised contractions were found in the distal oesophagus.

The relative number of propagating contractions detected proximally and distally, respectively, under different circumstances are shown in Figure 3. In the upper oesophagus more than $80 \%$ of the pressure complexes were propagating in all situations. A substantially higher proportion of distal complexes was classified as propagating in the upright position $(p<0.002)$ and during meals $(\mathrm{p}<0.001)$ compared with night time recumbency.

The relative number of non-propagating contractions in the distal oesophagus are shown in Figure 4 for the 17 subjects, who also had periods of recumbency during the day. During night time recumbency simultaneous contractions were more frequent than during daytime recumbency $(\mathrm{p}<0.02)$ and in the upright position not related to meal ingestion $(p<0.05)$. Simultaneous contractions were equally frequent during daytime recumbency and in the upright position and less frequent during meals than during the remaining daytime periods $(\mathrm{p}<0.005)$. The greatest difference was between meal ingestion and night time $(p<0.002)$. Reverse contractions were also more frequent during night time recumbency compared with daytime recumbency $(\mathrm{p}<0.01)$, while there were no differences between the daytime periods.

The $\mathrm{pH}$ in the distal oesophagus was below 4 during $1.9 \%$ (range $0 \cdot 3-14 \cdot 2$ ) of the total recording time. There was no correlation between severity of reflux and relative number of different kinds of pressure events as recorded over 23 hours. There was no difference between the sexes regarding the proportions of contractions being propagated at the proximal or distal levels.

\section{Discussion}

In previous investigations using digital conversion of pressure and $\mathrm{pH}$ signals and data storage
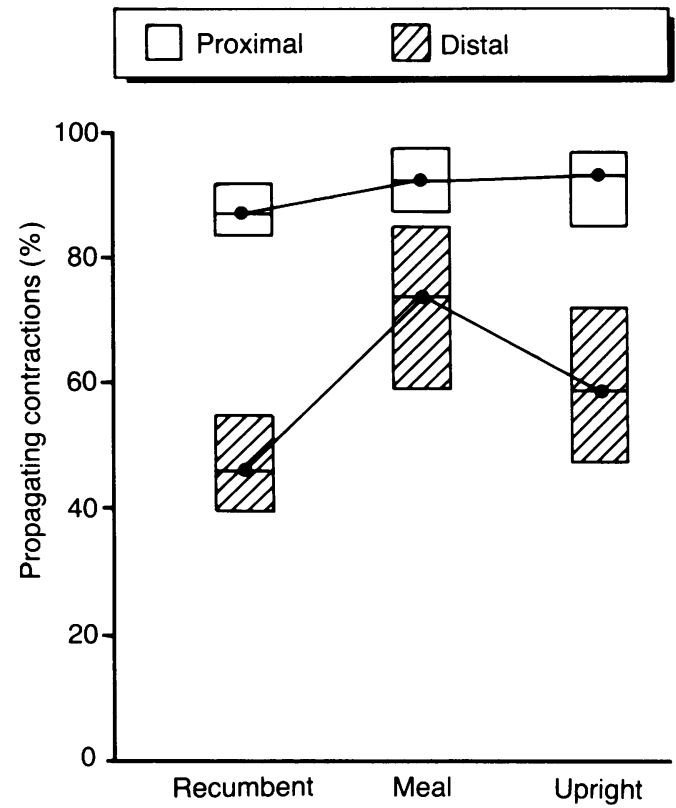

Figure 3: Relative number of propagating contractions detected proximally and distally under different circumstances. Medians and interquartile ranges are shown. 

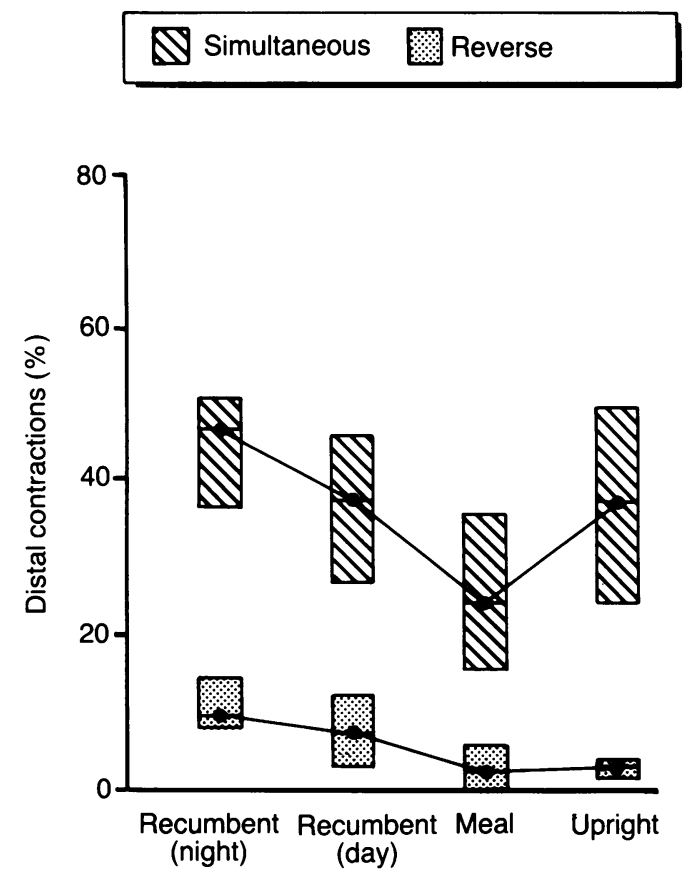

Figure 4: Relative number of simultaneous and reverse contractions in the distal oesophagus, recorded in 17 subjects, who also had periods of recumbency during the day. Median values and interquartile ranges are shown for different circumstances.

in a solid state memory, ${ }^{3-5}$ the signals were obtained from two pressure channels and one $\mathrm{pH}$ channel, and the recordings were restricted to the distal part of the oesophagus. It was therefore not known whether non-propagating contractions were as frequent in the proximal oesophagus as they were more distally. Furthermore, it was unclear to what extent the contractions recorded in the lower oesophagus were a continuation of contractions of the upper oesophagus that had already started. Our system made it possible to sample over a short distance in the lower oesophagus and at the same time detect what contractions originated in the more proximal part of the oesophagus.

In the present study non-propagating contractions were seen more frequently in the distal than the proximal part of the oesophagus. In addition, there were more local complexes distally than proximally. This pattern was especially conspicuous during night time recumbency. A pronounced change occurred with the transition from night to day, with a significant increase in the relative number of propagating contractions in the distal oesophagus, as Eypasch $e t a l^{5}$ also found. Furthermore, the proportion of localised complexes that could be detected in the distal oesophagus decreased with the transition from night to day and especially in connection with the ingestion of meals.

Observations from conventional manometry suggest that the smooth muscle part of the oesophagus is more prone to produce uncoordinated responses than the more proximal part. Double peaks are frequent in the distal oesophagus and have been found in normal subjects. Multiple peaks can be seen in the distal oesophagus in some patient groups ${ }^{13}$ despite the fact that normal bolus transport is preserved. In addition, oesophageal spasm mainly involves the smooth muscle part of the oesophagus. ${ }^{14}$ is These observations might explain why non-propagating contractions are relatively frequent in the distal oesophagus, and this explanation is also in agreement with the findings that many of the distal complexes were spontaneous contractions - that is, not a part of a pressure complex started at a more proximal level.

It is noticeable that the difference in the frequency of non-propagating contractions between night time and upright position was further accentuated in connection with meals. An even more important observation might be that non-propagating contractions, and particularly simultaneous contractions, were no more frequent during daytime recumbency than during the remaining time in the upright position. Therefore, the level of consciousness, and thereby the amount of time when regular swallowing takes place, seems more important for the composition of the recorded pressure activity than body position. For prolonged pressure monitoring this implies that a differentiation between daytime and night time recording is essential, while factors such as body position and meal ingestion seem to be of less practical importance for propagation analysis.

In most previous investigations the position of a $\mathrm{pH}$ probe ${ }^{56-19}$ or a combined $\mathrm{pH}$ and pressure probe $^{24}$ has been determined from the distance between the nose and the gastro-oesophageal sphincter, as measured on another day by infusion manometry. The most exact position of the probe is, however, achieved by simultaneous on-line identification of the gastro-oesophageal sphincter using a perfused pressure port, as carried out in the present study.

One problem related to the use of multiple recording sites is how to handle propagating pressure waves of sufficient amplitude to be detected proximally and distally and at the same time being subthreshold for detection at one or more intermediate levels. One way to handle this might be to develop programs allowing different amplitude thresholds to be defined for each channel. Splitting time related contractions into segmentary events, as carried out by the program used here, has presumably no basis in normal physiology. Of course, the limits chosen for classification of pressure events considerably influence the final results of an automatic propagation analysis as well.

Another consideration relates to the external conditions under which the registrations are to be performed. Restricting the behaviour of patients and normal volunteers during ambulatory recording, as others have done, ${ }^{4}$ will presumably reduce the interindividual variation. The concept of ambulatory recording as a physiological test, however, is violated if predetermined restrictions are made to the conditions of recording, as, for instance, when smoking and alcohol are prohibited and the number and timing of meals and sleep are determined beforehand. Such restrictions might also reduce the possibility of detecting motor disorders that occur intermittently and occur, only under more extreme circumstances. In addition, a point might easily be reached where further restrictions would be unrealistic under 
ambulatory conditions. We therefore chose to restrict the $\mathrm{pH}$ of ingested foods and beverages only, although the necessity of that measure has not yet been proved. ${ }^{20}$

As far as we know this is the first study to describe a fully automated analysis of all motility data obtained over 23 hours from three levels of the oesophagus in normal subjects. Smout et $a l^{4}$ also carried out continuous 23 hour intraoesophageal monitoring on normal subjects, although they recorded from only two points separated by $10 \mathrm{~cm}$. Eypasch et $a l^{5}$ used a different approach, which, strictly, was not prolonged monitoring, as they sampled for 128 seconds every 17 minutes only, corresponding to $12.5 \%$ of the recording time; this was due to the limited capacity of the equipment used.

In previous extended recordings of patients with non-cardiac chest pain ${ }^{12}$ the results were primarily based on quantitative judgment of selected parts of the tracings. If only selected parts of prolonged recordings are analysed the results will depend greatly on which parts are selected for more intensive analysis. Richter and Castell ${ }^{21}$ found that 2.5 times as many chest pain episodes were related to abnormal peristalsis in a group of patients with non-cardiac chest pain, when the criteria for sampling asymptomatic baseline periods were changed.

The method of prolonged monitoring of intraoesophageal pressures poses problems that differ from those of conventional manometry. Should the criteria for detection of pressure events be based on data from normal physiology, in particular those measured in connection with bolus transport? Or should the primary aim be to evaluate the efficiency of the integrated function of the oesophagus and the central nervous system - for instance, deduced from the ability of the oesophagus to organise from non-propagating to propagating pressure activity during the transition from night time to daytime, as proposed by Eypasch et al? ${ }^{5}$ Firstly, it will be necessary during future investigations to set different thresholds for amplitude at the different recording sites, as the minimum amplitude to accomplish bolus transportation varies along the oesophagus. ${ }^{8}$ Secondly, it might be desirable to set limits that provide as low an upper normal range for the occurrence of non-propagating pressure activity as possible, without regard for the amplitudes and peristaltic velocities that are necessary for bolus transport.

Digital sampling of data from one $\mathrm{pH}$ and three pressure measuring points in the oesophagus followed by fully automated propagation analysis is technically feasible. It could be shown by means of this method that a major part of the recorded pressure activity occurred in the distal oesophagus, where non-propagating contractions were also frequent. Propagating pressure waves were substantially more frequent during daytime than night time recumbency in the distal oesophagus, and most frequent during the ingestion of meals. The level of consciousness was found to be important and changes of body position during the daytime unimportant for the frequency of simultaneous contractions in the distal oesophagus. Due to the large amount of data provided by this newly developed technique the problems of data computation and data presentation now seem greater than the problems of data sampling.

This study was supported by a grant from Astra, Denmark.

1 Janssens J, Vantrappen G, Ghillebert G. 24-hour recording of esophageal pressure and $\mathrm{pH}$ in patients with noncardiac chest pain. Gastroenterology 1986; 90: 1978-84

2 Peters L, Maas L, Petty D, Dalton C, Penner D, Wu W, et al. Spontaneous noncardiac chest pain. Evaluation by 24-hour ambulatory esophageal motility and $\mathrm{pH}$ monitoring. Gastroenterology 1988; 94: 878-86.

3 Emde C, Bumm R, Kaufhold H-J, Hopert R, Bauerfeind P, Blum AL. The first ambulatory esophageal $\mathrm{pH} /$ manometry device with continuous digital recording and automated analysis: machine performance vs. human experience analysis: machine performance vs. hum

4 Smout AJPM, Breedijk M, Van der Zouw C, Akkermans LMA. Physiological gastroesophageal reflux and esophageal motor activity studied with a new system for 24-hour recording and automated analysis. Dig Dis Sci 1989; 34: 372-8

5 Eypasch EP, Stein HJ, DeMeester TR, Johansson K-E Barlow AP, Schneider GT. A new technique to define and clarify esophageal motor disorders. Am $\mathcal{F}$ Surg 1990; 159: $144-52$.

6 Fleshler B. Diffuse esophageal spasm. Gastroenterology 1987; 52: 559-64.

7 Richter JE, Blackwell JN, Wu WC, Johns DN, Cowan RJ, Castell DO. Relationship of radionuclide liquid bolus transport and esophageal manometry. F Lab Clin Med 1987; 109: 217-24.

8 Kahrilas PJ, Dodds WJ, Hogan WJ. Effect of peristaltic dysfunction on esophageal volume clearance. Gastroenterology 1988; 94: 73-80.

9 Wallin L, Madsen T, Boesby S, Sørensen O. Gastrooesophageal acid reflux and oesophageal peristalsis. Method for 12-hour simultaneous recording of $\mathrm{pH}$ and peristaltic activity in the oesophagus. Scand $\mathcal{F}$ Gastroenterol 1979; 14: 481-7.

10 Wallin L. Madsen T, Boesby S. Gastro-esophageal function in normal subjects after oral administration of ranitidine. Gut normal subjects

11 Kruse-Andersen S, Wallin L, Madsen T. Relationship between spontaneous non-propagating pressure activity in the oesophagus and acid gastro-oesophageal reflux in pathological and non-pathological refluxers. Gut 1987; 28: 147883.

12 Conover WJ. Practical non parametric statistics. Wiley: New York, 1971.

13 Loo FD, Dodds WJ, Soergel KH, Arndorfer RC, Helm JF, Hogan WJ. Multipeaked oesophageal peristaltic pressure waves in patients with diabetic neuropathy. Gastroenterology 1985; 88: 485-91.

14 Vantrappen G, Hellemans J. Oesophageal spasm and other muscular dysfunction. Clin Gastroenterol 1982; 11: 453-77.

15 Clouse RE, Staiano A. Contraction abnormalities of the esophageal body in patients referred for manometry. A new esophageal body in patients referred for manometry. A new approach

16 Robertson D, Aldersley M, Shepherd H, Smith C. Patterns of acid reflux in complicated oesophagitis. Gut 1987; 28: 1484-8.

17 Rokkas T, Anggiansah A, Uzoechina E, Owen WJ, Sladen $\mathrm{GE}$. The role of shorter than $24-\mathrm{H} \mathrm{pH}$ monitoring periods in the diagnosis of gastro-oesophageal reflux. Scand $\mathcal{J}$ Gastroenterol 1986; 21: 614-20.

18 De Caestecker JS, Blackwell JN, Pryde A, Heading RC. Daytime gastro-oesophageal reflux is important in oesophagitis. Gut 1987; 28: 519-26.

19 Johnsson F, Joelsson B, Isberg P-E. Ambulatory 24 hour intraesophageal $\mathrm{pH}$-monitoring in the diagnosis of gastrointraesophageal $\mathrm{pH}$-monitoring in the diagnosis
esophageal reflux disease. Gut 1987; 28: 1145-50

20 Atkinson M. Monitoring oesophageal pH. Gut 1987; 28: 509 14.

21 Richter JE, Castell DO. 24 hour ambulatory oesophageal motility monitoring: How should motility data be analysed? Gut 1989; 30: 1040-7. 